\title{
Synthesis and Characteristic of Carboxymethyl Cellulose from Baobab (Adansonia Digitata L.) Fruit Shell
}

\author{
Ahmed A. A. Youssif, Taiseer Hassan M.
}

\begin{abstract}
Baobab (Adansonia digitata L.) fruit shell was used as the raw material to produce cellulose. A $37.67 \%$ of cellulose was successfully extracted from baobab fruit shell through sodium hydroxide $(\mathrm{NaOH})$ pre-treatment and acidified sodium chlorite delignification. Cellulose was then converted to carboxymethyl cellulose (CMC) by etherification process using monochloroacetic acid (MCA), and various sodium hydroxide concentrations $(20,25,30,35$ and $40 \mathrm{~g} / 100 \mathrm{ml})$, in isopropyl alcohol (IPA) medium. The synthesized CMC yield increased with increasing amounts of sodium hydroxide ( $\mathrm{NaOH}$ ) concentration for the alkalization step. Structural information of cellulose and CMC was obtained using Fourier Transform Infrared spectroscopy (FT-IR), and the surface morphology was studied using scanning electron microscopy (SEM). The carboxymethylation process of cellulose was confirmed by FT-IR spectroscopy. The presence of a new and strong absorption band at $1600.92 \mathrm{~cm}-1$ for all CMCs samples is due to the $\mathrm{COO}^{-}$group, which substitutes $\mathrm{OH}$ groups at anhydroglucose unit (AGU). The degree of crystallinity for BFS cellulose was calculated to be $60.6 \%$ while the crystal size was calculated to be $31.12 \mathrm{~nm}$. XRD analysis confirmed that CMC crystallinity was reduced remarkably compared with cellulose. The viscosity average molecular weight $(\mathrm{M \eta})$ of baobab fruit shell cellulose obtained by Mark-Houwink equation using intrinsic viscosity data is $51,024 \mathrm{~g}$ mol-1. The optimum condition for carboxymethylation was found to be $35 \mathrm{~g} / 100 \mathrm{ml} \mathrm{NaOH}$, which provided the highest viscosity average molecular weight $(\mathrm{M \eta}=39,241 \mathrm{~g} \mathrm{mol-1})$ and degree of substitution $(\mathrm{DS}=0.94)$. The characteristic features of synthesized CMC suggest the possibilities of utilization as food additive.
\end{abstract}

Index Terms- Baobab fruit shell, Cellulose, Carboxymethylation, Lignocellulosic biomass.

\section{INTRODUCTION}

Baobab (Adansoniadigitata L.) is one of the important commercial non-timber forest products (NTFPs) [1]. Each mature tree produces more than an average of 250 capsules which may provide at least 30 kilograms of fruits. Fruits of baobab are very variable in size and shape [2]. The baobab fruit is composed of an outer shell (epicarp) (45\%), fruit pulp $(15 \%)$ and seeds $(40 \%)$ [2]. However, Baobab fruit shells (BFS) have no economic benefit [3], and as such they are often discarded wantonly around the harvesting areas and around the factory's sites, thereby littering the environment [4].

Ahmed A. A. Youssif, Master of degree Student, Red Sea University/ High Studies College/ Customs Lab., Port Sudan, Sudan, +249912921773.

Taiseer Hassan M., Department of Applied Chemistry, Red Sea University/ Assistant Professor, Port Sudan, Sudan, Phone/ +249916011965 .
Traditionally, the shells were burned and people produced soap from the ashes [5], or turned into baking soda [6], used as fishing floats [7], pots for food and drinks [8], dishes, vessels, souvenirs, mouse traps, jewel cases, lamp shades, music instruments [9] and a firewood substitute. [10].

Baobab fruit shell is a forestry biomass waste, generates during processing of fruit, contains appreciable amount of cellulose and hemicelluloses, which can be utilized into different uses. Most of the research has concentrated purely on the synthesis of activated carbon and adsorbent particles from Baobab fruit shell (BFS) [4], [11], [12]. This is the first attempt in BFS Lignocellulosic conversion.

Cellulose is the most abundant natural polymer in the biosphere, with a global production (and decomposition) of $\sim 1.5^{*} 10^{12}$ tons per year [13]. Cellulose is a polydisperse linear homopolymer, consisting of regio- and enantiosele- ctively $\beta$-1,4-glycosidic linked D-glucopyranose units (so-called anhydroglucose units [AGU]) (Fig. 1) [14]. In the solid state, AGU units are rotated by $180^{\circ}$ with respect to each other due to the constraints of $\beta$-linkage. Each of the AGU units has three hydroxyl $(\mathrm{OH})$ groups at $\mathrm{C}-2, \mathrm{C}-3$ and $\mathrm{C}-6$ positions [15]. A dimer of AGUs (cellobiose) can therefore be regarded as being the basic unit of the cellulose molecule. This also implies that the cellulose molecule could be considered as being a linear, unbranched, polymer with repeating units [16]. Hydroxyl groups present in cellulose macromolecules are involved in a number of intra- and intermolecular hydrogen bonds, which result in various ordered crystalline arrangements.

Four different crystalline allomorphs have been identified by their characteristic X-ray diffraction (XRD) patterns and solid-state ${ }^{13} \mathrm{C}$ nuclear magnetic resonance (NMR) spectra: celluloses I, II, III and IV. Cellulose I is the most abundant form found in nature. Cellulose II can be prepared by two distinct routes: mercerization (alkali treatment) and regeneration (solubilization and subsequent recrystallization). [17]. The chain ends of the cellulose molecule are chemically different. One end contains an anomeric $\mathrm{C}$ atom linked by the glycosidic bonds (nonreducing end) whereas the other end has a D-glucopyranose unit in equilibrium with the aldehyde function (reducing end group) [18].

The chain length of the cellulose molecule is expressed as the constituent of AGUs, which is commonly known as the degree of polymerization (DP) [20], DP of cellulose is heavily dependent on its source [21]. Native cellulose, isolated from cotton, wood, etc., has a DP $\geq 1000$ while 


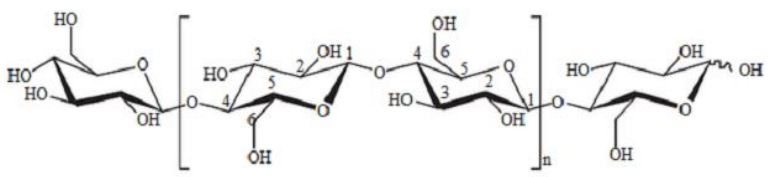

Fig.1. Structure of cellulose chain [19].

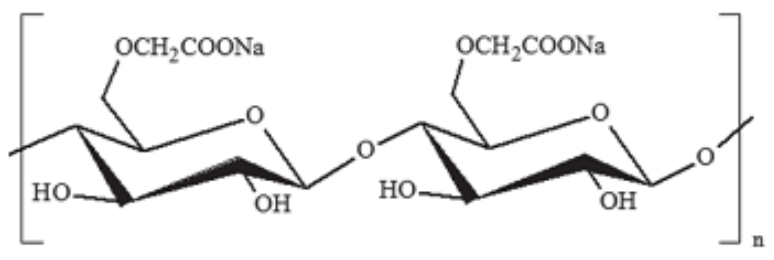

Fig.2. Unit structure of NaCMC [30].

regenerated cellulose fibers and powder have a DP of $250-600$ and $\leq 200$, respectively. The DP is always an average value since the cellulose substrate is a polydisperse mixture of polymers with varying chain lengths [20].

Carboxymethyl cellulose is a derivative of cellulose obtained by the chemical modification of natural cellulose. Purified Na-CMC is a white to cream color, tasteless, odourless, free-flowing powder [22], [23], [24], [25]. The numerous hydroxyl and carboxylic groups in CMC enable its ability to bind and absorb water [26]. CMC is also a constituent of many non-food products such as personal lubricants, toothpaste [27], anti-caking agent [28], paints, cosmetic industries [26], pharmaceutics, and mineral processing [29]. The molecular structure of carboxymethyl cellulose is shown in Fig. 2 [30].

CMC is prepared by activation of cellulose with an aqueous $\mathrm{NaOH}$ in the slurry of an organic solvent which reacts with the cellulose and monochloroacetic acid (MCA) as an etherifying agent. The first step in the carboxymethylation process is an alkalization where the hydroxyl groups of the cellulose chains are stimulated and altered into more reactive alkaline form $(\mathrm{CLL} \neg \mathrm{O} \neg)$.

$$
\mathrm{CLL} \neg \mathrm{OH}+\mathrm{NaOH}+\mathrm{H}_{2} \mathrm{O} \rightarrow \mathrm{CLL} \neg \mathrm{ONa}+\mathrm{H}_{2} \mathrm{O}
$$

This is followed by an etherification as in Equation (2) to obtain CMC and a side reaction as in (3), which results in sodium glycolate [31].

$$
\begin{aligned}
& \mathrm{CLL} \neg \mathrm{ONa}+\mathrm{ClCH}_{2} \mathrm{COOH} \rightarrow \mathrm{CLL} \neg \mathrm{OCH}_{2} \mathrm{COO}^{-} \mathrm{Na}^{+}+ \\
& \mathrm{NaCl}
\end{aligned}
$$

$$
\mathrm{NaOH}+\mathrm{ClCH}_{2} \mathrm{COOH} \rightarrow \mathrm{HOCH}_{2} \mathrm{COO}^{-} \mathrm{Na}^{+}+\mathrm{NaCl}(3)
$$

Many research projects have studied the production of $\mathrm{CMC}$ from agricultural waste cellulose sources such as corn peel [32], sugar beet pulp [33], water hyacinth [34], palm empty fruit bunch [35], sago Pulp [36], milox pulps [37], sugarcane bagasse [23], banana tree stem [38] and durian peel [39].

The purpose of the present research is to determine the yield of cellulose and chemical composition of baobab fruit shell as a biomass plant material in terms of their suitability for production of carboxymethyl cellulose. And the effects of various $\mathrm{NaOH}$ concentrations on produced $\mathrm{CMC}$.

\section{MATERIALS AND METHODS}

\section{A. Materials}

Baobab fruit capsules were collected from Gallabat, Al-Gadarf State. Coordinates: $12^{\circ} 58^{\prime} \mathrm{N} 36^{\circ} 09^{\prime} \mathrm{E} / 12.967^{\circ} \mathrm{N}$ $36.150^{\circ} \mathrm{E}$. Chemicals used during the present study were ethanol (PS PARK scientific limited), sodium hydroxide pellets 98\% (Labtech chemicals), acetic acid glacial RPE (CARLO ERBA Reagents), Acetone HPLC grade (AppliChem), Sodium chlorite 80\% technical grade (SDFCL sd line chem. Limited), benzene (KOCH LIGHT LTD), methanol (scharlu) isopropanol (CARLO ERBA Reagents), Chloroacetic acid (SCR, China). All chemicals were used as received without further purification.

\section{B. Preparations of samples}

The fruit capsules were crushed, pulp and seeds were removed. The fruit shell were cut into small pieces and washed by tab water and dried at room temperature for 48 hours. The samples were ground in the Kinematic M20 universal mill to pass a $60-80$ mesh standard sieve. The samples were then stored in sealed polyethylene storage bags and randomized by thoroughly shaking the bottle before each aliquot was removed for analysis.

\section{Isolation of cellulose}

The isolation of cellulose was done according to the method described by [40]. The washed and room temperature dried baobab fruit shell (BFS) were initially treated 4 times with $2 \%(\mathrm{w} / \mathrm{v}) \mathrm{NaOH}$ for 2 hours and washed with distilled water to neutral $\mathrm{pH}$. Secondly, the alkali treated BFS were further subjected to 4 times treatment of $2 \%(\mathrm{w} / \mathrm{v}) \mathrm{NaClO}_{2}$ treatment for a further 2 hours and washed to obtain neutral $\mathrm{pH}$ and dried. The white cellulose was dried in oven at $80 \mathrm{C}^{\circ}$.

\section{Preparation of carboxymethyl cellulose}

The synthesis of Carboxymethyl cellulose followed the procedure described by [25]. About $15.0 \mathrm{~g}$ of cellulose powder, $50 \mathrm{ml}$ of various concentrations of $\mathrm{NaOH}(20,25,30$, 35 and $40 \% \mathrm{w} / \mathrm{v}$ ) and $450 \mathrm{ml}$ of isopropyl alcohol were mixed in the beaker for $30 \mathrm{~min}$. The carboxymethylation react was started by adding $18.0 \mathrm{~g}$ of monochloroacetic acid (MCA) and continuously stirred for $30 \mathrm{~min}$. The mixture was covered with aluminum foil and heated up to reaction temperature of $55^{\circ} \mathrm{C}$ in an oven for $3.5 \mathrm{~h}$. Then, the mixture was separated into two phases. The liquid phase was removed and the solid phase was suspended in $100 \mathrm{ml}$ of methanol $(70 \% \mathrm{v} / \mathrm{v})$, and neutralized with glacial acetic acid then filtered using Buchner funnel. The final product was washed for 5 times by suspend in $300 \mathrm{ml}$ of ethanol $(70 \% \mathrm{v} / \mathrm{v})$ for 10 minutes to remove undesirable byproducts, and it was finally washed with $300 \mathrm{ml}$ of absolute methanol. The residue from filtration was dried at $55^{\circ} \mathrm{C}$ in the oven for overnight and then CMC was obtained. The yield, expressed as a percentage, was calculated based on the amount of cellulose using (4):

\%Yield CMC $=\frac{\text { weight of obtained CMC (g) }}{\text { weight of dried cellulose (g) }} \times 100(4)$ 


\section{E. Characterization of Cellulose and CMC}

\section{Determination of chemical composition}

The chemical composition of baobab fruit shell (BFS) powder and BFS cellulose was investigated. Dewaxing process with alcohol-benzene extraction, according to T 204 $\mathrm{cm}-97$ in a Soxhlet apparatus until the solvent was clear. The process took about 6 hours. Holocellulose content was determined by Wise's sodium chlorite method (Wise, Murphy $\&$ D'Addieco, 1946). The lignin (acid-insoluble), cellulose, ash contents and 1\% sodium hydroxide solubility were determined according to TAPPI standard methods T 222 om-02, T 203 cm-99, T 211 om-93 and T 212 om-02, respectively.

\section{CMC content}

Exactly $1.5 \mathrm{~g}$ of CMC was added to $100 \mathrm{ml}$ of $80 \%$ aqueous methanol solution. This mixture was stirred, kept for $10 \mathrm{~min}$ and filtered. The cake was washed with $100 \mathrm{ml}$ of fresh $80 \%$ aqueous methanol and dried to obtain pure CMC [41]. The CMC content was calculated as follows:

CMC Content $\%=\frac{W}{W_{\circ}} \times 100(5)$

Where $W_{\odot}(g)$ is the weight of sample before washing and $\mathrm{W}$ $(\mathrm{g})$ is the weight of washed sample.

\section{Determination of $\mathrm{NaCl}$ and $\mathrm{pH}$ of $\mathrm{CMC}$}

$2 \mathrm{~g}$ of CMC was added to $250 \mathrm{ml}$ of $65 \%$ aqueous methanol and kept for $5 \mathrm{~h} .100 \mathrm{ml}$ of this mixture in a liquid form was neutralized by diluted $0.1 \mathrm{~N} \mathrm{HNO}_{3}$ and titrated with $0.1 \mathrm{~N} \mathrm{AgNO}_{3}$ solution [41]. The $\mathrm{NaCl}$ content was calculated as follows:

$$
\mathrm{NaCl}(\%)=1.461 \times \frac{\mathrm{V}}{\mathrm{M}}
$$

Where $\mathrm{V}(\mathrm{ml})$ is the amount of $\mathrm{AgNO}_{3}$ solution and $\mathrm{M}(\mathrm{g})$ is the weight of the dried sample.

The $\mathrm{pH}$ of a $1 \%$ solution was estimated using Hanna edge $\mathrm{pH}$ meter.

\section{F. Physical Characterization of BFS cellulose and CMC}

\section{Determination Degree of Substitution (DS)}

Degree of Substitution of BFS-CMC samples were done according to COEI-1-CMC: 2009 [42]. Five gram of the sample was weighted to the nearest $0.1 \mathrm{mg}$ and taken into a $500 \mathrm{ml}$ conical flask. Now $350 \mathrm{ml}$ of methanol or ethanol $(80$ $\%$ v/v) was added and the suspension was mechanically stirred for $30 \mathrm{~min}$. The sample was decanted through a sintered glass crucible under gentle suction. The suction of air through the crucible was avoided at the end of the decanting process. The decanted liquid was tested for chloride ions by the silver nitrate test. This treatment was repeated until the achievement of negative chloride test in the extracted liquid. Normally three treatments were sufficient. The sodium carboxymethyl cellulose was transferred into the same crucible and the adhered extraction liquid to the substance was displaced with acetone. The sample in crucible was dried to constant weight in an oven at $110 \mathrm{C}$ and cooled in desiccators and weighed after $2 \mathrm{~h}$. A lot of attention was paid during weighting every time because of the fact that sodium carboxymethyl cellulose is hygroscopic in nature.

Now $2 \mathrm{~g}$ of the bone dry substance obtained with the above mentioned alcohol extraction procedure was weighed to the nearest of $0.1 \mathrm{mg}$ and taken in a silica crucible. Initially the material was charred carefully with a small flame and afterwards with a large flame for $10 \mathrm{~min}$. Cooled and then moistened the residue with $3-5 \mathrm{ml}$ of concentrated sulfuric acid. Heated cautiously until the fuming was finished. After some cooling, about $1 \mathrm{~g}$ of ammonium carbonate powder was distributed over the whole content of the crucible. Heated again, initially with a small flame until the fuming was finished and then at a dull red heat for $10 \mathrm{~min}$. The treatment with sulfuric acid and ammonium carbonate was repeated if the residual sodium sulfate still contains some carbon. The crucible was cooled in desiccators and weighed. Instead of adding ammonium carbonate and heating further with a flame, the crucible could be placed for $1 \mathrm{~h}$ in an oven at about $600 \mathrm{C}$. The sodium content of the alcohol-extracted sample was calculated by (7):

$\%$ Sodium $=\frac{a \times 32.38}{b}$

Where, $a=$ weight of residual sodium sulfate, $b=$ weight of the alcohol-extracted dry sample.

Degree of substitution was calculated by (8):

$$
\text { Degree of substitution }=\frac{162 \times \% \text { Sodium }}{2,300-(80 \times \% \text { Sodium })}(8)
$$

\section{Determination of Moisture Content}

The moisture content of the CMC was determined according to ASTM D 1439-0 [43]. About $3 \mathrm{~g}$ of the sample was placed in an open sample bottle and heated in an oven at $105{ }^{\circ} \mathrm{C}$ for $2 \mathrm{~h}$. The sample was then cooled, and the bottle was closed and weighed. The sample was then replaced in the oven for $30 \mathrm{~min}$, cooled and reweighed. This procedure was continued until the mass loss was not more than $5 \mathrm{mg}$ for 30 min drying time. The percent moisture, $M$, was calculated using (9) as follows:

\section{Moisture Content $\%=\frac{\text { Mass loss on heating }(\mathrm{g})}{\text { sample used }(\mathrm{g})} \times 100(9)$}

\section{Determination of the viscosity average molecular weight $\left(M_{\eta}\right)$}

The ratio of the viscosity of a polymer solution to that of the solvent is called relative viscosity $\left(\eta_{r}\right)$. This value minus 1 is called the specific viscosity $\left(\eta_{s p}\right)$, and the reduced viscosity $\left(\eta_{\text {red }}\right)$, or viscosity number, is obtained by dividing $\eta_{s p}$ by the concentration of the solution $(C)$. The intrinsic viscosity, or limiting viscosity number, is obtained by extrapolating $\eta_{\text {red }}$ to zero concentration. [44]. 


$$
[\eta]=\lim _{c \rightarrow 0} \frac{\eta_{s p}}{c} \equiv \lim _{c \rightarrow 0} c^{-1} \ln \eta_{r e l}
$$

The intrinsic viscosity as functions of average molecular weight are usually represented by widely used Mark-Houwink-Sakurada empirical equation 11. [33].

$$
[\eta]=K M^{a}
$$

Cellulose samples were dispersed in pre-cooled $6 \%$ $\mathrm{NaOH} / 4 \%$ urea system [45] and cooled at $-12{ }^{\circ} \mathrm{C}$ for $24 \mathrm{~h}$. The range of concentration investigated was from $0.01-$ $0.002(\mathrm{~g} / \mathrm{ml})$. The viscosity of cellulose samples were measured at $25{ }^{\circ} \mathrm{C}$ using an Ubbelodhe viscometer. To estimate intrinsic viscosity $(\eta)$, Huggins and Kraemer plots were equipped. Average molecular weight of the cellulose samples was determined using the relation between intrinsic viscosity $[\eta]$ and viscosity-average molecular weight. The Mark-Houwink constant, $K$ and $\alpha$ for cellulose were $2.45 \times$ $10^{-2} \mathrm{mlg}^{-1}$ and 0.815 , respectively [46]. The degree of polymerisation (DP) of cellulose pulp was determined from intrinsic viscosity (g) data [37] using (12).

$$
D P^{0.905}=0.75[\eta]
$$

Intrinsic viscosities of CMC samples were obtained by dissolving the samples in $0.5 \mathrm{~N}$ sodium hydroxide $(\mathrm{NaOH})$ solution, followed by dilution series. The range of concentration investigated was from $1.0-0.2(\mathrm{~g} / \mathrm{dL})$. The flow times, $\mathrm{t}$, were recorded with reproducibility $\pm 0.2 \mathrm{~s}$. Mark-Houwink constant, $K$ and $\alpha$ for CMC were $5.37 \times 10^{-4}$ $\mathrm{dLg}^{-1}$ and 0.73, respectively [47].

\section{Fourier transform infrared (FTIR) spectroscopy}

FTIR analysis was carried out using a Shimadzu ir prestige 21 spectrometer. The samples were dried in an oven at $60{ }^{\circ} \mathrm{C}$. About $0.2 \mathrm{mg}$ of sample and $2 \mathrm{mg}$ of $\mathrm{KBr}$ were mixed and ground finely and the mixture was compressed to a form a transparent disk. [48] A total of 64 scans were taken from $400-4000 \mathrm{~cm}-1$ with a resolution of $4 \mathrm{~cm}-1$ for each sample.

\section{5. $X$-ray diffraction $(X R D$}

The crystallinity of baobab fruit shell cellulose (BFSc) studied using an X-ray diffractometer (Shimadzu X-ray Diffractometer XRD-7000) equipped with $\mathrm{Cu}-\mathrm{K}$ radiation $(\lambda=1.1541874 \AA)$ in the $2 \theta$ range $10.090^{\circ}-80.103^{\circ}$. The operating voltage was $40 \mathrm{kV}$, and the current was $40 \mathrm{~mA}$. The samples were scanned within the high angle $2 \theta$ range to get all characteristic diffractions of the materials at 0.5 scan speed and 0.014 increments. The empirical method [49] was used to obtain the crystallinity index of the samples CI, as shown in Eq. 13:

$$
\mathrm{CI}=\frac{\mathrm{I}_{200}-\mathrm{I}_{\mathrm{ANI}}}{\mathrm{I}_{200}} \times 100(13)
$$

Where $I_{200}$ is the maximum intensity of the principal peak 200 lattice diffraction at $2 \theta=22.006$ for cellulose $\mathrm{I}, \mathrm{I}_{\mathrm{AM}}$ is the intensity of diffraction attributed to amorphous cellulose at $2 \theta=18.3[50]$.

The crystalline size (d) were determined using the mathematical relationship between the peak width (full width at half maximum, FWHM) of the diffraction peaks and the crystal size (d) is known as the Scherrer equation [51]

$$
\mathrm{D}=\frac{\mathrm{K} h}{\mathrm{~B} \cos \theta}
$$

Where, $\mathrm{K}$ is the constant $0.94, \theta$ is Bragg's angle, and $\mathrm{B}$ is the intensity of the full width at half of the maximum (FWHM) corresponding to a high intensity peak of the diffraction plane 200. [52].

\section{Scanning electron microscopy (SEM)}

TESCAN Vega3 XMU scanning electron microscope was used to observe the morphology (granule surface and shape) of the cellulose and CMC from Baobab fruit shell.

\section{RESUlTS AND DISCUSSION}

\section{A. Chemical composition of BFS biomass and BFS cellulose}

Pretreatment BFS powder by $2 \% \mathrm{NaOH}$ causes the breaking of intramolecular hydrogen bonding which directly changes the bonding network and strength. Since there is no complete removal of hemicellulose and lignin, the alkali-pretreated fibers undergo bleaching treatment with $2 \%$ acidified sodium chlorite that further decreases the hemicellulose and lignin content [53].

The investigated baobab fruit capsules contains $17.88 \%$ pulp, $43.78 \%$ seeds, $3.95 \%$ fibers and $34.39 \%$ shell, which agree with literature [54]. The composition of baobab fruit shell (BFS) biomass is given in Table I. The major components were found to be holocellulose $59.0 \%$, the acid-insoluble lignin (Klason) is $37.44 \%$, $\alpha$-cellulose $34.73 \%$, hemicellulose $24.27 \%$, ash $2.43 \%$ and extractives $5.61 \%$. It should be noted, that on average, nut shells and fruit stones tend to contain more lignin, and less cellulose content than wood [55]. The extracted cellulose fibers from baobab fruit shell showed an average of $37.67 \%$ of yield, the average molecular weight of BFS cellulose dissolved in $\mathrm{NaOH} / \mathrm{Urea}$ solution is approximately $51,024 \mathrm{~g} / \mathrm{mol}$. The composition and viscosity of the fibers after bleaching is quite suitable for the production of carboxymethyl cellulose [13].

\section{B. Synthesis of CMC and CMC yield}

CMC was obtained by alkalization of cellulose with 20 , $25,30,35$ and $40 \%(\mathrm{w} / \mathrm{v}) \mathrm{NaOH}$, in the presence of isopropyl alcohol, followed by carboxymethylation process using monochloroacetic acid (MCA). Mercerization functions as a swelling agent [32], and simultaneously dissolves alkali-soluble lignin and some amount of hemicellulose [53]. The swelling causes fibrilization and a decrease in the degree of polymerization of cellulosic fibers 
Table I Chemical composition of baobab fruit shell (BFS) and BFS cellulose

\begin{tabular}{|l|c|c|}
\hline \multicolumn{1}{|c|}{ Composition } & BFS & BFS cellulose \\
\hline Ash & 2.62 & 0.17 \\
\hline Extractive & 2.98 & No data \\
\hline Acid-insoluble lignin & 37.44 & 10.36 \\
\hline Holocellulose & 59.20 & No data \\
\hline$\alpha$-cellulose & 34.27 & 71.35 \\
\hline Hemicellulose & 24.93 & 14.93 \\
\hline Moisture & 3.24 & 2.66 \\
\hline
\end{tabular}

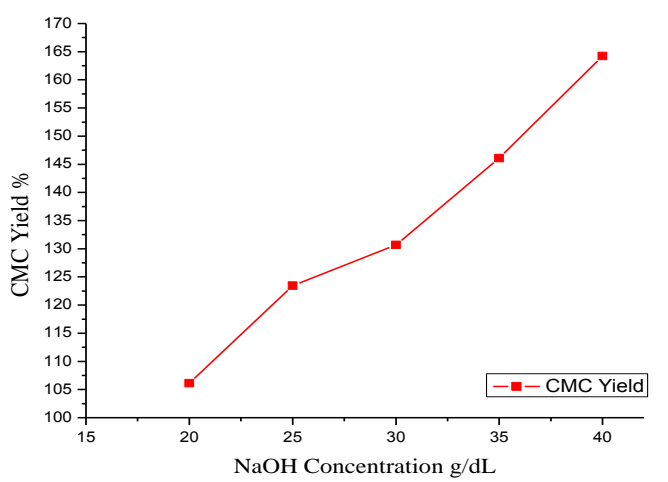

Fig. 3. BFS CMC yield

that increase the contact surface area. [53].

The effect of varying the concentration during mercerizeation of the cellulose pulp appeared to have a variable effect on the produced CMC characters. The results provided that increasing of $\mathrm{NaOH}$ concentrations affected to increase the percent yield of CMC (as shown in Fig. 3). This observation could corroborate substitution of carboxymethyl group from carboxymethylation because of the higher molecular weight than hydroxyl group of carboxymethyl group [29].

\section{Degree of substitution (DS}

The Degree of Substitution (DS) is the average number of hydroxyl groups in the cellulose structure substituted by carboxymethyl or sodium carboxymethyl groups at the carbon 2,3 and 6. Each anhydroglucose ( $\beta$-glucopyranose) unit has three reactive (hydroxyl) groups so theoretically DS value can be in the range from zero (cellulose itself) to three (fully substituted cellulose) [23]. Commercial products have a DS in the range of 0.4 to 1.4 , with a DS of 0.7 to 0.8 perhaps the most common [56]. Below approximately 0.4 the polymer is swellable but insoluble, above this the polymer is fully soluble with its hydroaffinity increasing with increasing DS [22].

The degree of substitution (DS) of CMC obtained in this work were in the range of 0.34- 0.94, as presented in table (2).The DS of CMC increased with increasing in concentration of $\mathrm{NaOH}$ and attained a maximum DS of 0.94 at an alkali concentration of $35 \%$ due to the availability of more $-\mathrm{OH}$ groups. $\mathrm{NaOH}$ causes saponification of intramolecular hydrogen bonding between hydroxyl groups and oxygen atoms, as well as intermolecular ester bonding that binds both the lignin and hemicellulose [53]. Above 35\% $\mathrm{NaOH}$ the DS value decreased. The reason for this observation is that an undesired side reaction happened which dominated the CMC production. Sodium glycolate was the product of such undesired reaction. With further increasing of $\mathrm{NaOH}$ concentration, more reduction in DS value was observed. It can be explained by degradation effect of high concentration of alkali reagent on CMC polymer chains [23][29]. It must be noticed that DS value is affected by cellulose source [23]. In terms of $\mathrm{CMC}$ purity and $\mathrm{NaCl}$ content, there is no a consistent trend for all the CMC samples.

Table II Characterization of BFS carboxymethyl cellulose

\begin{tabular}{|l|c|c|c|c|c|}
\hline \multirow{2}{*}{ Parameters } & \multicolumn{5}{|c|}{$\mathrm{NaOH}$ Concentration w/v } \\
\cline { 2 - 6 } & $20 \%$ & $25 \%$ & $30 \%$ & $35 \%$ & $40 \%$ \\
\hline CMC yield \% & 122 & 123.46 & 130.46 & 146.09 & 164.21 \\
\hline Purity \% & 92.03 & 91.94 & 88.01 & 89.90 & 86.20 \\
\hline $\mathrm{NaCl} \mathrm{Content} \%$ & 0.33 & 3.27 & 3.10 & 3.04 & 3.13 \\
\hline Moisture \% & 5.57 & 6.18 & 5.35 & 8.32 & 9.58 \\
\hline $\mathrm{pH}$ solution 1\% & 6.43 & 6.50 & 6.40 & 7.1 & 7.5 \\
\hline $\mathrm{DS}$ & 0.34 & 0.41 & 0.68 & 0.94 & 0.91 \\
\hline $\begin{array}{l}\text { Intrinsic } \\
\text { viscosity }[\eta]\end{array}$ & 0.3092 & 0.6892 & 1.0594 & 1.2118 & 1.1905 \\
\hline $\begin{array}{l}\text { Molecular } \\
\text { weight g/mol }\end{array}$ & 6,038 & 18,113 & 32,639 & 39,241 & 38,299 \\
\hline
\end{tabular}

\section{Viscosity average molecular weight $\left(M_{\eta}\right)$}

The average molecular weight $\left(M_{\eta}\right)$ is an important parameter of cellulose. It affects swelling, dissolubility of cellulose in the solvents, its structure and other properties [57]. Fig. 4 and 5, displays the Huggins and Kraemer plots for BFS cellulose and synthesized $\mathrm{CMC}$ in $\mathrm{NaOH}$, at $25^{\circ} \mathrm{C}$. Extrapolation of both reduced $\left[\eta_{\text {red }}\right]$ and inherent $\left[\eta_{\text {inh }}\right]$ viscosities to zero concentration provide the intrinsic viscosity $[\eta][58]$. The $[\eta]$ values could be estimated from the intercept of the plots [59].

Intrinsic viscosity, a measure of the hydrodynamic volume occupied by a molecule, is a measure of the capacity of a polymer molecule to enhance the viscosity [33]. The average molecular weight of BFS cellulose isolated by acidified sodium chlorite method is $51,024 \mathrm{~g} / \mathrm{mol}$. The molecular weights of CMC synthesized with different $\mathrm{NaOH}$ concentrations were listed in Table II. The intrinsic viscosity of $\mathrm{CMC}$ increased with increasing $\mathrm{NaOH}$ concentration up to $35 \%$ of $\mathrm{NaOH}$ concentration.

The intrinsic viscosity of CMC solution increased as the DS increased. This is because of greater amount of carboxymethyl groups substituted on the hydroxyl groups of the cellulose polymer [58]. Moreover, these carboxymethyl groups which act as a hydrophilic group increased the ability of CMC to immobilize more water in the system [58].

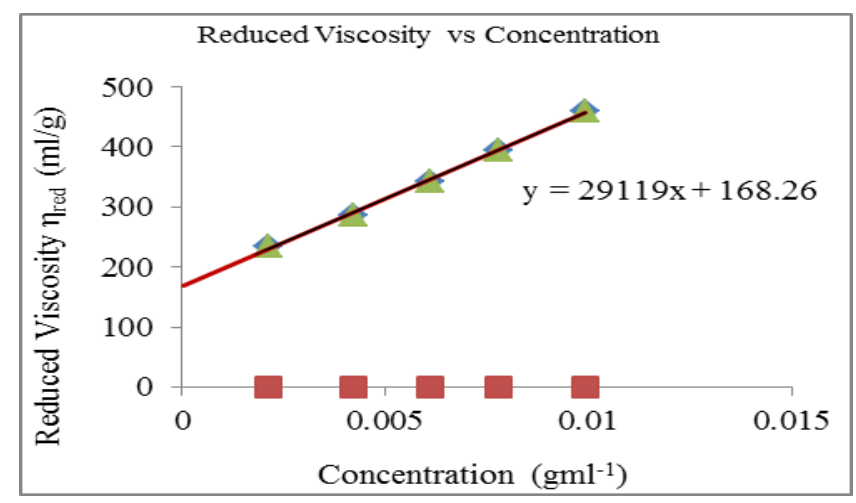

Fig. 4 Huggins and Kraemer plots for BFS cellulose in $\mathrm{NaOH} /$ urea system. 


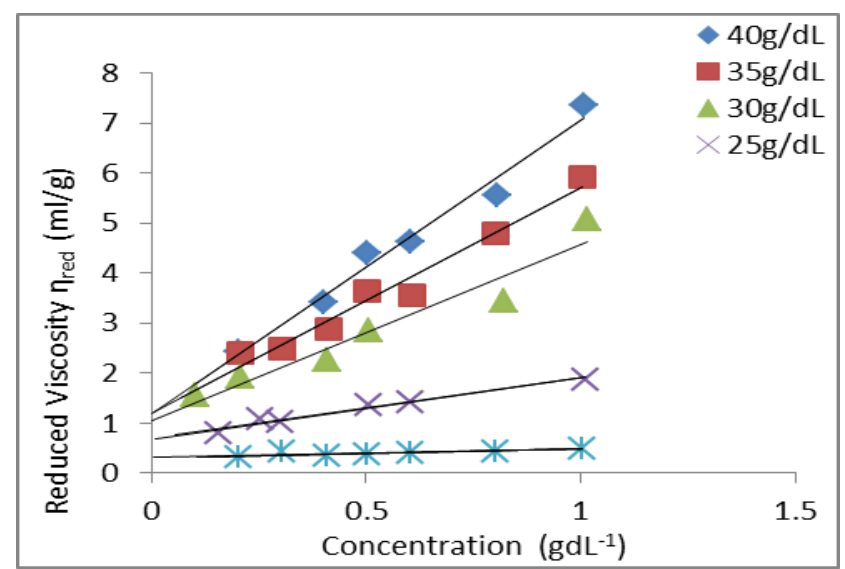

Fig. 5 Huggins and Kraemer plots for BFS CMC in $0.5 \mathrm{~N}$ $\mathrm{NaOH}$ solution.

However, beyond $35 \%$ of $\mathrm{NaOH}$ concentration used in the carboxymethylation synthesis causes the intrinsic viscosity of CMC to decrease. This is due to the effect of polysaccharide degradation at higher concentration of $\mathrm{NaOH}$ [28]. Furthermore, the intrinsic viscosity of CMC was found to have the same trend as DS for the increase in the concentration of $\mathrm{NaOH}$ [58]

\section{E. FT-IR spectroscopy analysis}

Infrared spectroscopy is one of the most versatile techniques used in chemistry and certainly one of the most important analytical methods available. It is a versatile experimental technique and it is relatively easy to obtain reliable spectra from samples in virtually any state.

The IR-spectrum of BFS cellulose gives very typical peaks for a number of special groups. As shown in figure 6, the band at $669.30 \mathrm{~cm}^{-1}$ is $\mathrm{OH}$ out-of-plane bending band [33]. An absorption band observed at $896.89 \mathrm{~cm}^{-1}$ corresponding to $\beta$-glycosidic linkage. [60]. The prominent band at 1058.92 $\mathrm{cm}^{-1}$ represents ring vibration and $\mathrm{C}-\mathrm{OH}$ bending. The band at $1163.08 \mathrm{~cm}^{-1}$ is attributable to the $\mathrm{C}-\mathrm{O}$ and $\mathrm{C}-\mathrm{O}-\mathrm{C}$ stretching. There are $\mathrm{C}-\mathrm{H}$ bending vibration bands at 1377.17 $\mathrm{cm}^{-1}$. The band at $1318 \mathrm{~cm}^{-1}$ represents $\mathrm{OH}$ in plane bending or $\mathrm{CH}$ bending. The peak at $1423 \mathrm{~cm}^{-1}$ shows $\mathrm{CH}_{2}$ bending. The characteristic peak at $1625 \mathrm{~cm}^{-1}$ is $-\mathrm{O}$ - tensile vibration band neighboring to $\mathrm{H}$ group.

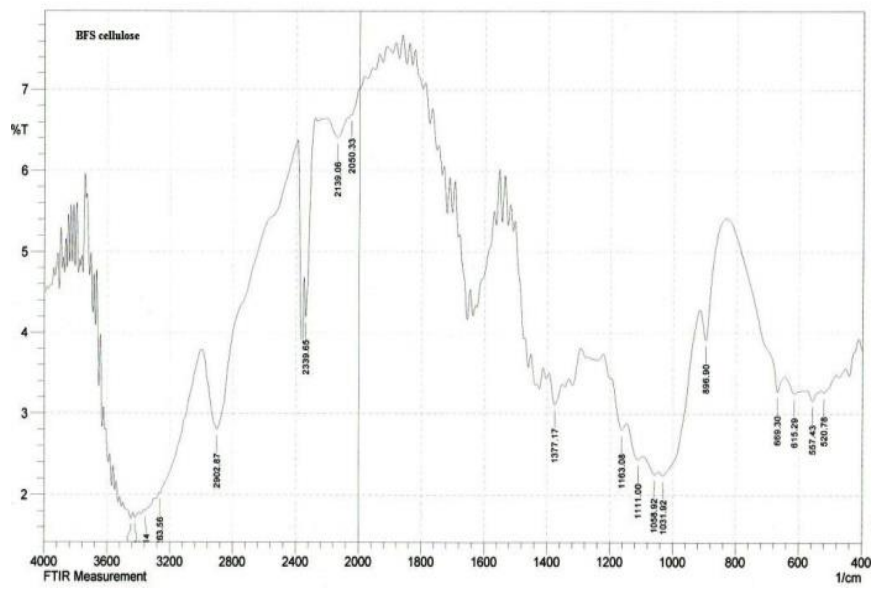

Fig. 6. IR spectra of BFS cellulose.

The peak at $2902.87 \mathrm{~cm}^{-1}$ is due to the stretching of $\mathrm{C}-\mathrm{H}$ [61]. A broad absorption band at $3417.86 \mathrm{~cm}-1$ was due to the stretching of -OH groups, which was directly related to interand intra-molecular hydrogen bonding [53]. The additional peaks at wavelength of $2339.65 \mathrm{~cm}^{-1}$ and $2139.06 \mathrm{~cm}^{-1}$ might be done to the existence of the contamination [35], due to $\mathrm{CO}_{2}$ during treatment, processing or from breathing. The absorption peaks around 3400, 2900, 1430, 1370, $890 \mathrm{~cm}^{-1}$ are associated with the characteristics of native cellulose I as seen in all cellulose spectra [36].

The peak area of CMC was less than the area of the peak that appeared for cellulose confirming the reduction in hydrogen bonding [53]. The IR spectrums of CMC produced using different $\mathrm{NaOH}$ concentration (Fig. 7-11) are similar to each others. All the synthesized CMC samples have shown the typical absorptions peaks of carboxymethylated cellulose. Salt of carboxyl group had wave number about $1600 \mathrm{~cm}^{-1}$ and $1400-1450 \mathrm{~cm}^{-1}$ [62]. the broad absorption band at $3401-3423.65 \mathrm{~cm}^{-1}$, due to the stretching frequency of the $-\mathrm{OH}$ group, suggesting that the $\mathrm{OH}$ groups at $\mathrm{C}_{2}, \mathrm{C}_{3}$, and $\mathrm{C}_{6}$ on the pyranose ring in $\mathrm{CMC}$ were substituted by $\mathrm{CH} 2 \mathrm{COO}-$ [32]. The band at 2899.01-2927.94 $\mathrm{cm}^{-1}$ attributable to $\mathrm{C}-\mathrm{H}$ stretching vibration [63]. The presence of a new and strong absorption band at $1600.92 \mathrm{~cm}^{-1}$ for all CMCs samples is due to the COO-group [28]. The bands around 1403 - 1421.54 and $1323.17-1327.03 \mathrm{~cm}^{-1}$ are assigned to $-\mathrm{CH}_{2}$ scissoring and $-\mathrm{OH}$ bending vibration, respectively [48]. The band around $1058 \mathrm{~cm}^{-1}$ is due to $>\mathrm{CH}-\mathrm{O}-\mathrm{CH}$ stretching [61], at the $\beta$-glycosidic bonds [53].

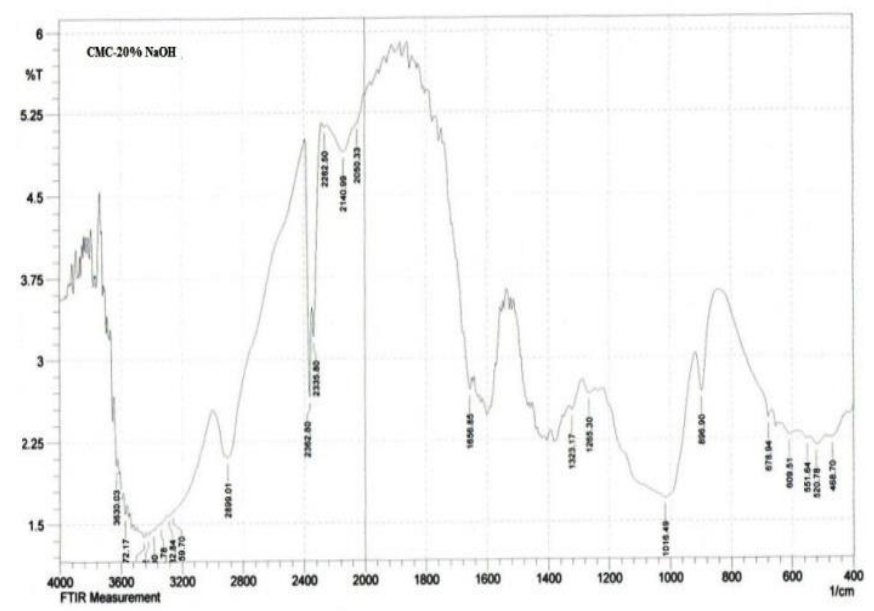

Fig. 7. IR spectra of BFS CMC alkalized with $20 \% \mathrm{NaOH}$

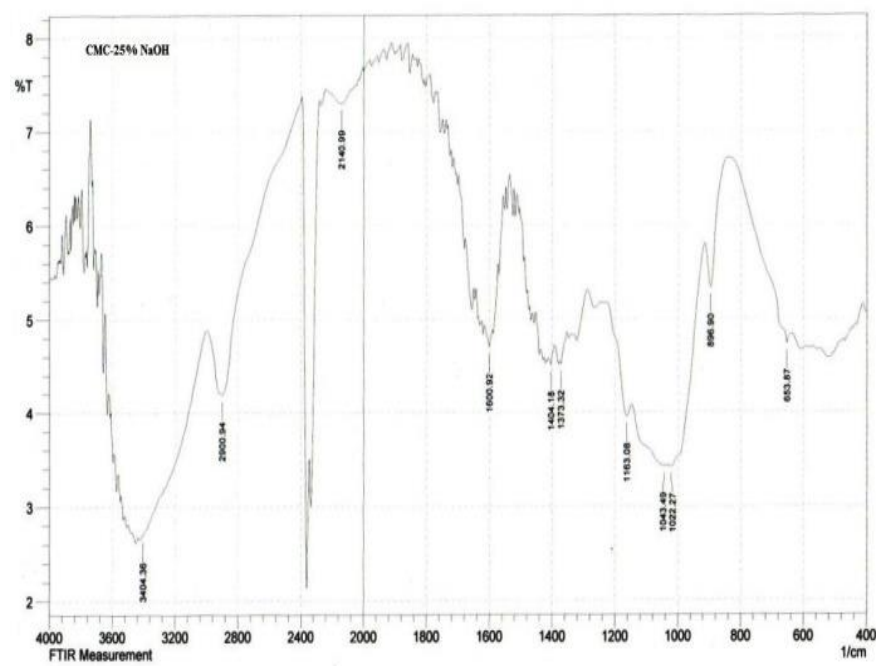

Fig. 8. IR spectra of BFS CMC alkalized with $25 \% \mathrm{NaOH}$ 


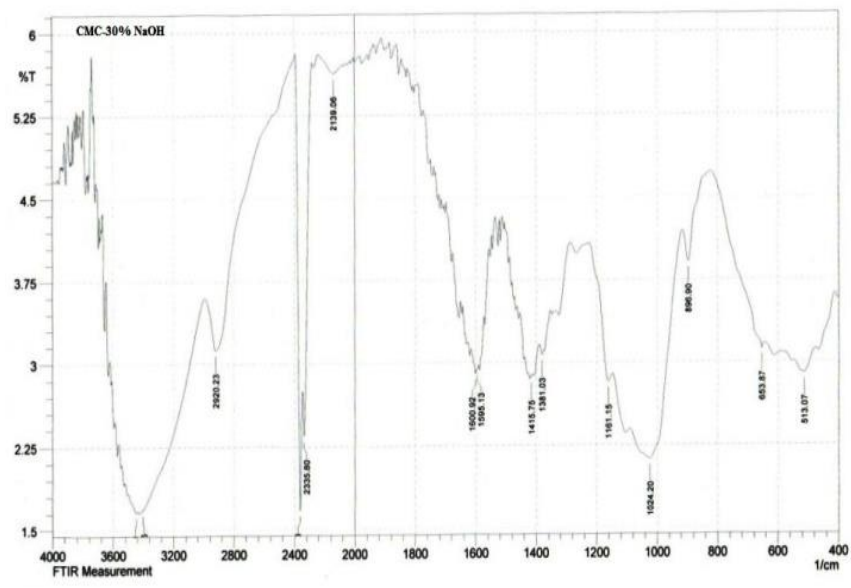

Fig. 9. IR spectra of BFS CMC alkalized with $30 \% \mathrm{NaOH}$

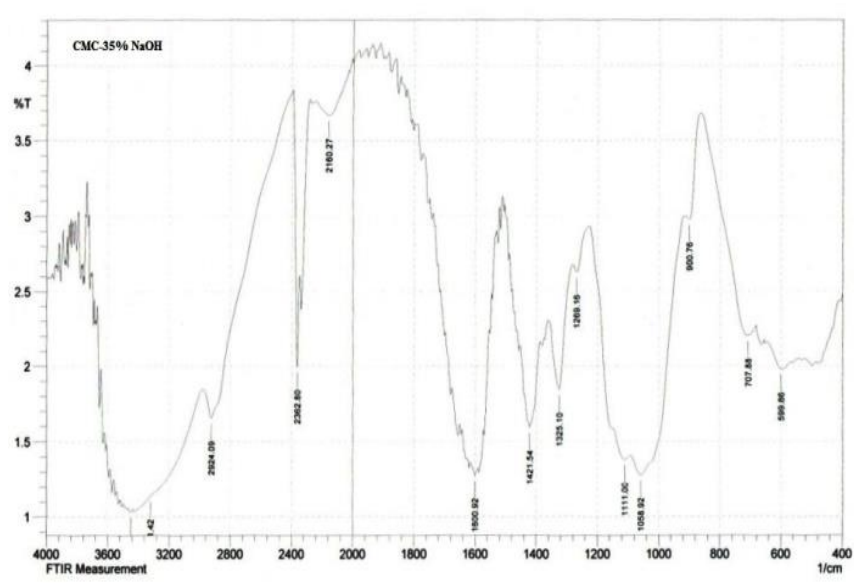

Fig. 10. IR spectra of CMC alkalized with $35 \% \mathrm{NaOH}$

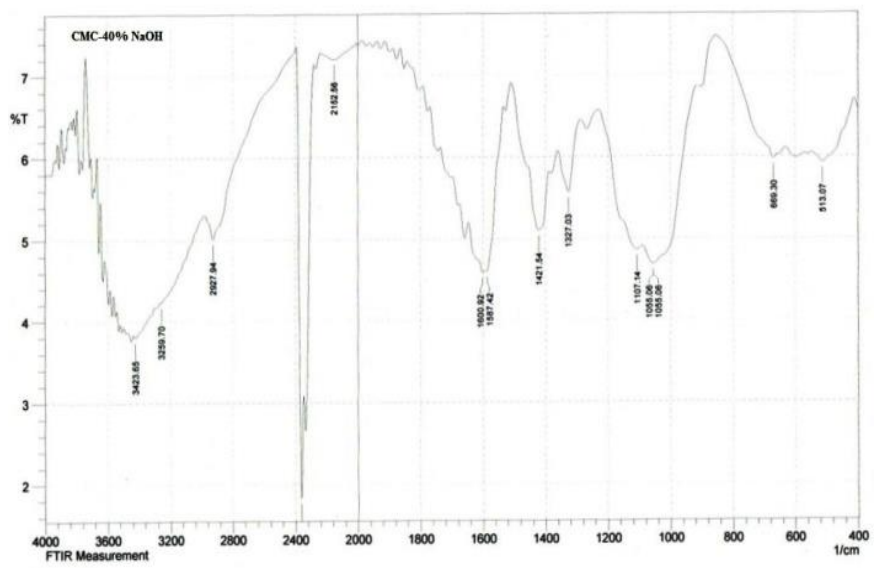

Fig. 11. IR spectra of BFS CMC alkalized with $40 \% \mathrm{NaOH}$

\section{F. XRD Analysis}

X-ray diffraction (XRD) analysis is a special technique for estimating the degree of crystallinity in polymer [41]. Cellulose is semi-crystalline in nature [64]. The crystallinity of cellulose was related to inter- and intra-molecular hydrogen bonding [65]. Cellulose I can be transformed to cellulose II by treatment with an aqueous sodium hydroxide solution. The major difference between cellulose I and II is due to the hydrogen bonding between the cellulose chains [66].

X-ray diffractograms of BFS cellulose and synthesized $\mathrm{CMC}$ with various $\mathrm{NaOH}$ concentrations $(20,25,30,35$ and $40 \%$ ) were presented in Fig. 12. The XRD pattern of BFS cellulose showed typical reflections characteristic of polymorphous structure of cellulose I, at $2 \theta=14.97,16.19$, 22.006 , and $34.222^{\circ}$ that belonged to planes [110], [110], [200], and [004], respectively (Fig. 12, curve 1) [67], [68]. The absence of doublet in the main peak at $2 \theta=23^{\circ}$ indicates the absence of any cellulose II [36]. The crystallinity index was calculated by the Segal method [49] and crystallite size was calculated for the three main crystal reflections (110, 1ī0 and 200) by means of the Scherrer equation. Table III.

Most of the earlier studies on the crystalline structure of cellulose I have used lower $2 \theta$ range, especially when the powder diffractometer method was used. The other lines were either too weak or overlap each other so that positions of these lines were difficult to define. As we used a wide $2 \theta$ range in this study, there are peaks at $2 \theta 43.711,64.083$ and 77.217. Chen R. 1998 [69], reported that The diffraction lines at above $2 \theta=40$ degrees are difficult to assign with specific lattice planes as many lines are close to each other.

The diffraction spectra of CMC samples show a destruction of the crystalline structure of the original cellulose [64]. The characteristic peaks for native cellulose have almost disappeared and transformed into an amorphous phase [64]. All of spectrum had lower peak of intensity (au) values than cellulose (Fig. 12, curve 1) indicating that were less crystalline [31].. The decrease of crystallinity on the alkalization and carboxymethylation process of cellulose were due to the cleavage of hydrogen bonds and this also results in the extending the distance between cellulose molecules. As shown in fig. 12, curve 2-6, it is also observed that the degree of crystallinity of cellulose I (more crystalline) was changed to cellulose II (more amorphous) [65]. This can be confirmed by the shift that occurred for peaks of 200 in $2 \theta$ $=22.006^{\circ}$ in cellulose $\mathrm{I}$, to $\sim 2 \theta=20.2^{\circ}$ in $\mathrm{CMC}$.

Table III. Crystallinity Index and crystallite Size of BFS cellulose

\begin{tabular}{|l|l|l|l|}
\hline \multirow{2}{*}{$\begin{array}{l}\text { Crystallinity } \\
\%\end{array}$} & \multicolumn{3}{|c|}{ Crystallite size (nm) } \\
\cline { 2 - 4 } & $14.97(110)$ & $16.188(1 \overline{1} 0)$ & $22.006(002)$ \\
\hline 60.6 & 41.82 & 58.63 & 31.12 \\
\hline
\end{tabular}

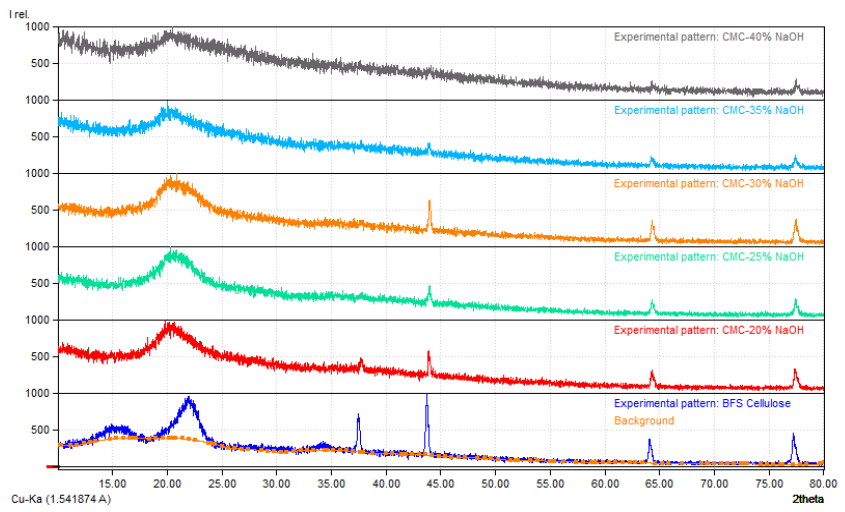

Fig.12. XRD patterns of BFS cellulose and CMC.

Shifting of the peaks was attributed to the increase in the distance between the cellulose molecules by the destruction of the 1-4 glycosidic bonding [53], [63]. Reported that the crystallinity of CMC decreases with the increase of the degree of substitution. Therefore CMC has excellent solubility as lower crystallinity represents higher solubility [41]. 


\section{G. SEM analysis}

SEM analysis is a technique for examining granules morphology since it has a large depth of field, which allows a large amount of sample to focus at one time. The SEM also produces images of high resolution, which means that closely spaced features can be examined at high magnification [70].

Fig. 13 (a-f) represents the morphological structures of BFS cellulose and synthesized CMC. BFS cellulose showed coarse particles of different sizes with rough surface, may be caused of using strongly chemicals and high temperature in cellulose extraction process [71]. The surface morphology of prepared CMC can be clearly seen that the obtained products are rod-like (or ribbon shaped) and surfaces are more extended, rough and collapsed which is similar to other reported images for a typical CMC molecule [29], [64], [70].

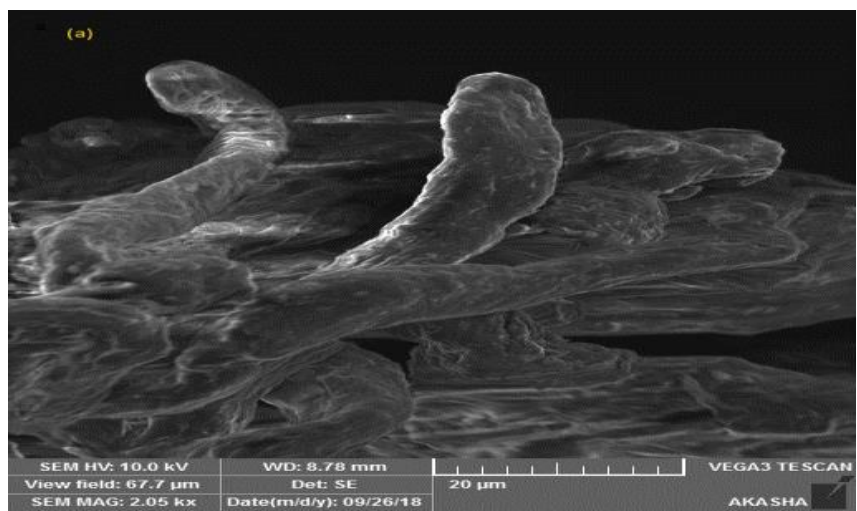

Figures13a. SEM image of synthesized CMC by $20 \mathrm{~g} / \mathrm{dL}$ $\mathrm{NaOH}$.

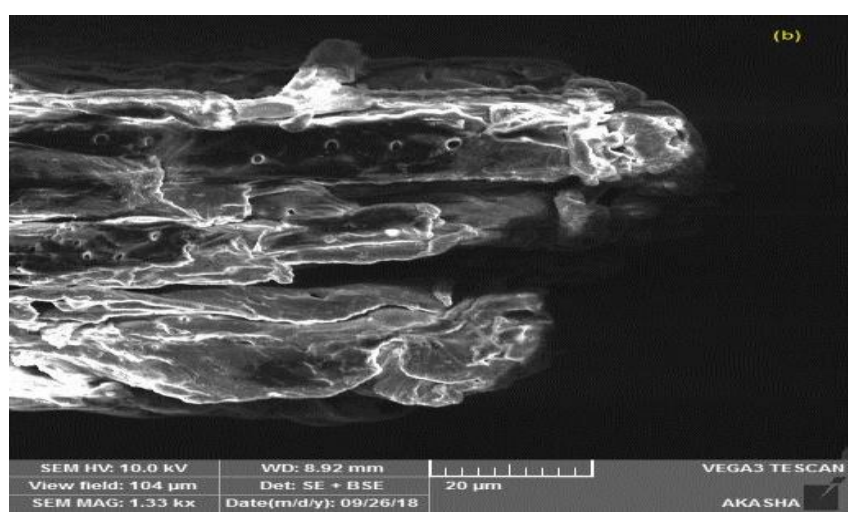

Figures13b. SEM image of synthesized CMC by $25 \mathrm{~g} / \mathrm{dL}$ $\mathrm{NaOH}$.

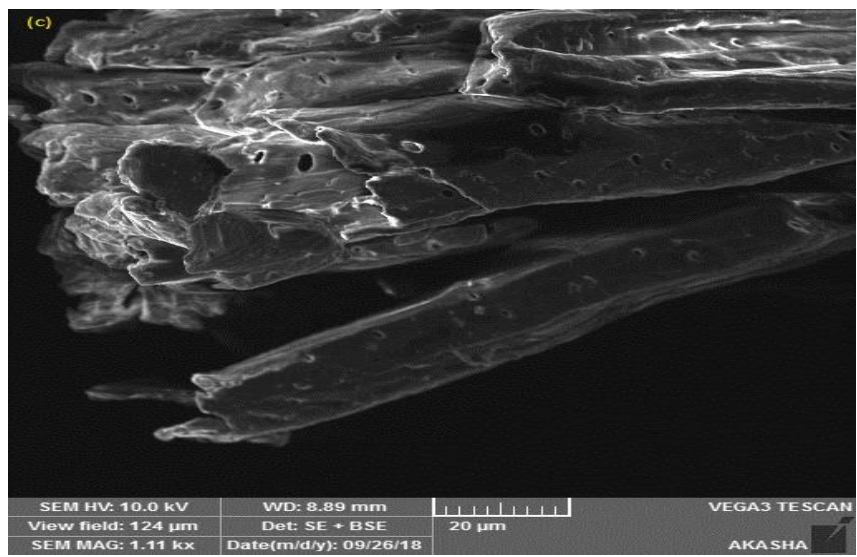

Figures13c. SEM image of synthesized CMC by $30 \mathrm{~g} / \mathrm{dL}$

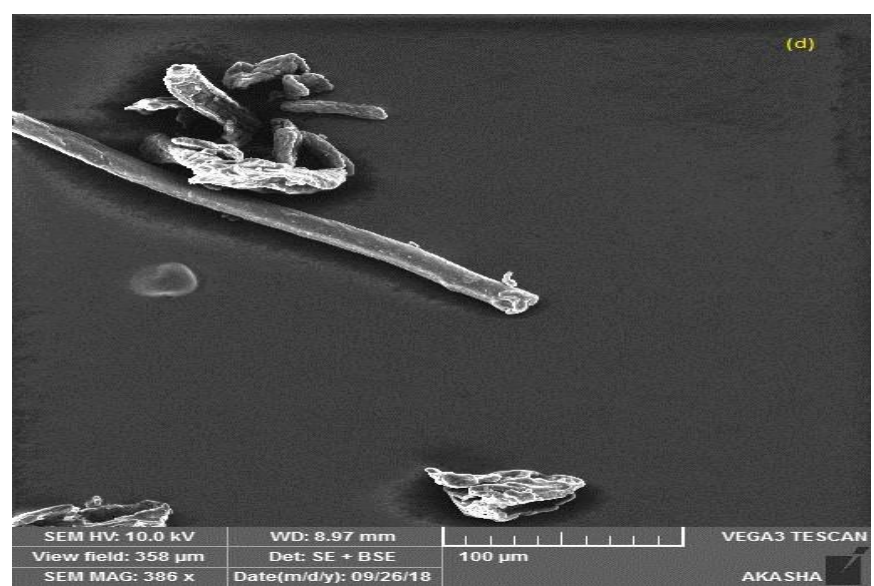

Figures13d. SEM image of synthesized CMC by $35 \mathrm{~g} / \mathrm{dL}$ $\mathrm{NaOH}$.

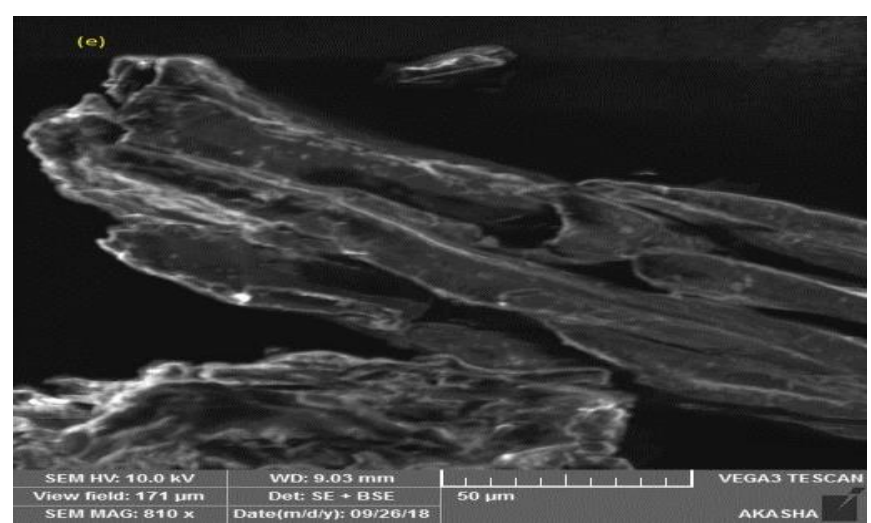

Figures13e. SEM image of synthesized CMC by $40 \mathrm{~g} / \mathrm{dL}$ $\mathrm{NaOH}$.

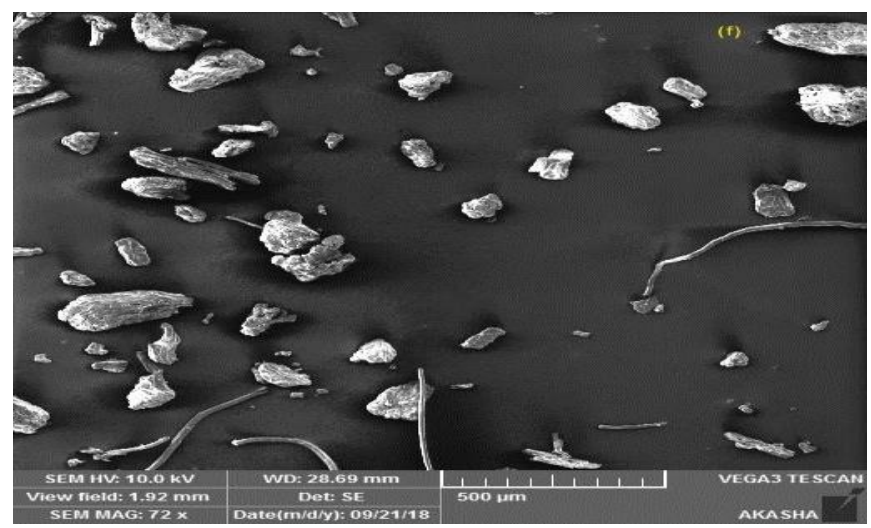

Figures13f. morphological structures of BFS cellulose

\section{CONCLUSION}

Baobab fruit shell is an abundant agricultural waste. The present study reveals the potential of BFS as a source of cellulose. The isolated cellulose can be derivatized by typical chemical modification reactions like carboxymeth- ylation. The analysis result supported that the carboxym- ethylation was achieved. The carboxymethylation was significantly affected by $\mathrm{NaOH}$ concentration. The DS value of CMC increased with increasing of $\mathrm{NaOH}$ concentration in the range of 20 to $45 \mathrm{~g} / 100 \mathrm{ml}$ and declined after synthesized with 35 $\mathrm{g} / 100 \mathrm{ml} \mathrm{NaOH}$ concentration. Also, the viscosity average molecular weight of CMC depended on the $\mathrm{NaOH}$ concentration. The crystallinity of CMC decreased after modification. 


\section{ACKNOWLEDGMENT}

The authors are grateful to the Red Sea University for financial support of this work.

\section{REFERENCES}

[1] G. P. P. Kamatou, I. Vermaak, and A. M. Viljoen, "An updated review of Adansonia digitata: A commercially important African tree," South African J. Bot., vol. 77, no. 4, pp. 908-919, 2011.

[2] N. A. Gurashi and M. A.Y.Kordofani, "Morphological Variation in Fruit Shapes of Adansonia digitata L. From Blue Nile and North Kordofan States, Sudan.,’ J. For. Prod. Ind., vol. 3, no. 2, pp. 106-111, 2014.

[3] sam Y. Q. and Kabbashi, N.A., Mirghani, M.E.S., Alam Md. Z and I. A. Bello, "Characterization of the Baobab fruit shells as adsorption material,” Int. Food Res. J., vol. 24, no. December, pp. 472-474, 2017.

[4] E. Vunain, D. Kenneth, and T. Biswick, "Synthesis and characterization of low-cost activated carbon prepared from Malawian baobab fruit shells by $\mathrm{H} 3 \mathrm{PO} 4$ activation for removal of $\mathrm{Cu}$ (II) ions: equilibrium and kinetics studies," Appl. Water Sci., vol. 7, no. 8, pp. 4301-4319, 2017.

[5] H. Pander, "How Baobab Sales Help Build a House," Baobab Stories about the African Tree of Life, 2016. [Online]. Available: https://baobabstories.com/en/baobab-sales-help-build-house/.

[6] A. cuni Sanchez, "The baobab tree in Malawi," in Fruits, 66th ed., 2011, pp. 405-416.

[7] H. Pander, "Baobab Fruit as Birdhouses!," Baobab Stories about the African Tree of Life, 2015. [Online]. Available: https://baobabstories.com/en/baobab-fruit-as-birdhouses/.

[8] J. Gebauer, K. El-Siddig, and G. Ebert, "Baobab ( Adansonia digitata L .): a Review on a Multipurpose Tree with Promising Future in the Sudan," Gartenbauwissenschaft, vol. 67, no. 4, pp. 155-160, 2002.

[9] J. Gebauer et al., "Africa's wooden elephant: the baobab tree (Adansonia digitata L.) in Sudan and Kenya: a review," Genet. Resour. Crop Evol., vol. 63, no. 3, pp. 377-399, 2016.

[10] Gruenwald J. and M. Galizia, "Adansonia digitata L . Baobab," in Market Brief in the European Union for selected natural ingredients derived from native species, 2005, p. 35.

[11] N. A. Kabbashi, M. E. S. Mirghani, M. Z. Alam, S. Y. Qudsieh, and I. A. Bello, "Characterization of the Baobab fruit shells as adsorption material," Int. Food Res. J., vol. 24, no. December, pp. 472-474, 2017.

[12] N. Tarachand, S. Dipak, M. Bhoj, P. Hills, A. Road, and P. Nagar, "Baobab fruit shell (Adansonia digitata) as a Natural Adsorbent for Copper and Lead Removal from Industrial Effluent," Res. J. Chem. Environ. Sci., vol. 4, no. 29, pp. 32-38, 2016.

[13] T. Heinze and A. Koschella, "Carboxymethyl ethers of cellulose and starch - A review," Macromol. Symp., vol. 223, pp. 13-39, 2005.

[14] D. Klemm, B. Philipp, T. Heize, U. Heinze, and W. Wagwnknecht, Comprehensive Cellulose Chemistry. Fundamentals and Analytical Methods. Weinheim, Germany, 2001.

[15] M. Granström, "Cellulose Derivatives: Synthesis , Properties and Applications," Helsinki University Printing House, Helsinki, 2009.

[16] H. A. Krässig, Cellulose, Structure, Accessibility and Reactivity. Amsterdam: Gordon and Breach Publishers, 1993.

[17] S. Park, J. O. Baker, M. E. Himmel, P. A. Parilla, and David K Johnson*1, "ResearchCellulose crystallinity index: measurement techniques and their impact on interpreting cellulase performance," Biotechnol. Biofuels, vol. 3, p. 10, 2010.

[18] T. Heinze, "Cellulose: Structure and Properties," Adv. Polym. Sci., vol. 271, pp. 1-52, 2016.

[19] E. H. Fatriasari W., "Lignocellulosic biomass for bioproduct: its potency and technology development," J. Lignocellul. Technol., vol. 1, no. 1, pp. 1-14, 2016.

[20] M. Kihlman, "Dissolution of cellulose for textile fibre applications," Karlstad University, 2012.

[21] V. K. Varshney and S. Naithani, "Chemical Functionalization of Cellulose Derived from Nonconventional Sources," in Cellulose Fibers: Bio- and Nano-Polymer Composites, Dehra Dun 248006 , India: pringer-Verlag, 2011, pp. 43-61.

[22] M. Onigbinde and A. Vivian, "Synthesis of Industrial Raw Material from Cellulosic Agricultural Wastes: Focus on Carboxymethyl Cellulose,” Nov. J. Eng. Appl. Sci., vol. 4, no. 1, pp. 1-6, 2015.

[23] S. A. Asl, M. Mousavi, and M. Labbafi, "Synthesis and Characterization of Carboxymethyl Cellulose from Sugarcane," J. Food Process. Technol., vol. 8, no. 8, 2017.
[24] E. C. M. and O. J. O. Obele C. M., "Synthesis and Characterization of Carboxymethyl Cellulose from Cassava Stem (Manihot esculenta)," Lignocellulose, vol. 6, no. 2, pp. 109-118, 2017.

[25] P. Rachtanapun, "Blended Films of Carboxymethyl Cellulose from Papaya Peel ( CMCp ) and Corn Starch,” Kasetsart J. (Nat. Sci.), vol. 266, pp. 259-266, 2009.

[26] C. M. Y. Huang, P. X. Chia, C. S. S. Lim, and Q. Nai, "Synthesis and Characterisation of Carboxymethyl Cellulose from Various Agricultural Wastes," Cellul. Chem. Technol, vol. 51, no. 7-8, pp 665-672, 2017.

[27] I. Hossainn et al., "Isolation of Cellulosic Material from Agro-wastes and their Derivatization,” Dhaka Univ. J. Sci, vol. 63, no. 1, pp. 43-46, 2015.

[28] A. Bono, P. H. Ying, F. Y. Yan, C. L. Muei, R. Sarbatly, and D. Krishnaiah, "ORIGINAL A RTICLE Synthesis and Characterization of Carboxymethyl Cellulose from Palm Kernel Cake,” vol. 3, no. 2073 pp. 5-11, 2009.

[29] P. Rachtanapun and R. Suriyatem, "Value Added of Durian Husks : Synthesis of Carboxymethyl Cellulose from Durian Husk," Dep. Packag. Technol., p. 55, 2009

[30] A. KULIKOWSKA, I. WASIAK, and T. CIACH, "Synthesis of carboxymethylcellulose nanoparticles using various coiling agents," Inż. Ap. Chem., vol. 53, no. 4, pp. 268-269, 2014.

[31] P. Rachtanapun, S. Luangkamin, K. Tanprasert, and R. Suriyatem, "Carboxymethyl cellulose film from durian rind," YFSTL, vol. 48, no. 1, pp. 52-58, 2012.

[32] P. Rojsitthisak, S. Khunthon, K. Noomun, and S. Limpanart, "Response surface method to optimize the preparation of carboxymethyl cellulose from corn peel agricultural waste," scienceasia, vol. 43, pp. 8-14, 2017.

[33] N. A. Toğrul H., "Flow properties of sugar beet pulp cellulose and intrinsic viscosity - molecular weight relationship," Carbohydr. Polym. 54, vol. 54, pp. 63-71, 2003.

[34] A. H. Saputra, L. Qadhayna, and A. B. Pitaloka, "Synthesis and Characterization of Carboxymethyl Cellulose ( CMC ) from Water Hyacinth Using Ethanol-Isobutyl Alcohol Mixture as the Solvents,' Int. J. ofChemical Eng. Appl., vol. 5, no. 1, pp. 36-40, 2014.

[35] M. Y. Eliza, M. Shahruddin, J. Noormaziah, and W. D. W. Rosli, "Carboxymethyl Cellulose (CMC) from oil palm empty fruit bunch (OPEFB) in the new solvent dimethyl sulfoxide (DMSO)/tetrabutylammonium fluoride (TBAF)," J. Phys. Conf. Ser., vol. 622 , no. $1,2015$.

[36] A. K. Veeramachineni, T. Sathasivam, and S. Muniyandy, "Optimizing Extraction of Cellulose and Synthesizing Pharmaceutica Grade Carboxymethyl Sago Cellulose from Malaysian Sago Pulp,' Appl. Sci., vol. 6, no. 170, p. 18, 2016.

[37] S. Dapra, V. Santos, and J. C. Parajo, "Carboxymethylcellulose from totally chlorine free-bleached milox pulps," Bioresour. Technol., vol. 89, pp. 289-296, 2003.

[38] H. A. Mulyatno, O. I. Pratama, and Inayati, "Synthesis of Carboxymethyl Cellulose ( CMC ) from Banana Tree Stem : Influence of Ratio of Cellulose with Sodium Chloroacetate To Properties of Carboxymethyl Cellulose," Equilibrium, vol. 16, no. 2, pp. 33-37, 2017.

[39] D. A. Putri and Z. Kurniyati, "Effect of Sodium Chloroacetate towards the Synthesis of CMC (Carboxymethyl Cellulose) from Durian (Durio zibethinus) peel Cellulose,” Int. J. Innov. Res. Adv. Eng., vol. 03, no. 3 , pp. 2349-2763, 2016

[40] S. M. Mohomane, L. Z. Linganiso, T. Buthelezi, and T. E. Motaung, "Effect of extraction period on properties of sugarcane bagasse and softwood chips cellulose," Wood Res., vol. 62, no. 6, pp. 931-938, 2017.

[41] M. I. H. Mondal, M. S. Yeasmin, and M. S. Rahman, "Preparation of food grade carboxymethyl cellulose from corn husk agrowaste," Int. J. Biol. Macromol., vol. 79, pp. 144-150, 2015.

[42] COEI-1-CMC: 2009, "Carboxymethylcellulose (cellulose gum)," Int ENOLOGICAL CODEX, pp. 1-14, 2009

[43] ASTM D 1439 - 03, "Standard Test Methods for Sodium Carboxymethylcellulose,” ASTM International, 2003.

[44] Carraher C. E. Jr., Polymer Chemistry, Sixth Edit. Florida: Marcel Dekker, Inc, 2003

[45] J. Zhou and L. Zhang, "Solubility of Cellulose in NaOH/Urea Aqueous Solution," Polym. J., vol. 32, no. 10, pp. 866-870, 2000.

[46] J. Zhou, L. Zhang, and Jie Cai, "Behavior of cellulose in $\mathrm{NaOH} / \mathrm{Urea}$ aqueous solution characterized by light scattering and viscometry," J Polym Sci, Part B Polym Phys, vol. 42, pp. 347-353, 2003. 
[47] T. E. Eremeeva and T. O. Bykova, "SEC of mono-carboxymethyl cellulose ( CMC ) in a wide range of $\mathrm{pH}$; Mark - Houwink constants,' Carbohydr. Polym., vol. 36, pp. 319-326, 1998.

[48] V. Pushpamalar, S. J. Langford, M. Ahmad, and Y. . Lim, "Optimization of reaction conditions for preparing carboxymethyl cellulose from sago waste," Carbohydr. Polym., vol. 64, pp. 312-318, 2006.

[49] L. Segal, J. J. Creely, A. E. Martin, and C. M. Conrad, “An Empirical Method for Estimating the Degree of Crystallinity of Native Cellulose Using the X-Ray Diffractometer,” Text. Res. J., vol. 29, pp. 786-794, 1959.

[50] C. Azubuike, O. Odulaja, and A. Okhamafe, "Physicotechnical, spectroscopic and thermogravimetric properties of powdered cellulose and microcrystalline cellulose derived from groundnut shells .," Int. Pharm. Excipients Counc., vol. 3, no. September, pp. 106-115, 2012.

[51] P. K. Kimani, P. G. Kareru, S. E. Madivoli, P. K. Kairigo, and E. G. Maina, "Comparative Study of Carboxymethyl Cellulose Synthesis from Selected Kenyan Biomass," Chem. Sci. Int. J., vol. 17, no. 4, pp. $1-8,2016$

[52] M. S. Nazir, B. A. Wahjoedi, A. W. Yussof, and M. A. Abdullah, "Eco-friendly extraction and characterization of cellulose from oil palm empty fruit bunches," BioResources, vol. 8, no. 2, pp. 2161-2172, 2013.

[53] I. Gulati, J. Park, S. Maken, and M.-G. Lee, "Production of Carboxymethylcellulose Fibers from Waste Lignocellulosic Sawdust Using $\mathrm{NaOH} / \mathrm{NaClO} 2$ Pretreatment," Fibers Polym., vol. 15, no. 4, pp. 680-686, 2014.

[54] E. De Caluwé, K. Halamova, and P. Van Damme, "Adansonia digitata L. - A review of traditional uses , phytochemistry and pharmacology," Afrika Focus, vol. 23, no. 1, pp. 11-51, 2010.

[55] D. B. Corbett, N. Kohan, G. Machado, C. Jing, A. Nagardeolekar, and B. M. Bujanovic, "Chemical composition of apricot pit shells and effect of hot-water extraction,” Energies, vol. 8, no. 9, pp. 9640-9654, 2015.

[56] R. L. Feller and M. Wilt, Evaluation of Cellulose Ethers for Conservation (1990), Second pri. J. Paul Getty Trust, 1990.

[57] D. Khai, D; Nhan, P; Trinh, "Average molecular weight and molecular weight distribution of the Vietnamese acacia pulps," Vietnam J. Chem., vol. 55, no. 6, pp. 135-138, 2017.

[58] K. M. Hong, "PREPARATION AND CHARACTERIZATION OF CARBOXYMETHYL CELLULOSE FROM SUGARCANE BAGASSE," Universiti Tunku Abdul Rahman, 2013.

[59] S. Zhang, F. Li, J. Yu, G. U. Li-xia, and S. Zhang, "DISSOLVED STATE AND VISCOSITY PROPERTIES OF CELLULOSE IN A NaOH COMPLEX SOLVENT," Cellul. Chem. Technol., vol. 43, no. 7-8, pp. 241-249, 2009.

[60] C. Lee, K. Dazen, K. Kafle, A. Moore, D. K. Johnson, and S. Park, "Correlations of Apparent Cellulose Crystallinity Determined by XRD, NMR, IR, Raman, and SFG Methods,” Adv. Polym. Sci., vol. 271, pp. 115-132, 2016.

[61] M. Mohkami and M. Talaeipour, "Investigation of the Chemical Structure of Carboxylated and Carboxymethylated Fibers From Waste Paper Via Xrd and Ftir Analysis," BioResources, vol. 6, no. 2, pp. 1988-2003, 2011.

[62] Krisdayanti Gutawa, A. T. Willy, and G. R. Nikita, "Synthesis and characterization of sodium carboxymethylcellulose from pod husk of Cacao (Theobroma cacao L.)," African J. Food Sci., vol. 6, no. 6, pp. 99-103, 2012.

[63] R. K. Singh and A. K. Singh, "Optimization of Reaction Conditions for Preparing Carboxymethyl Cellulose from Corn Cobic Agricultural Waste," Waste Biomass Valor, 2012.

[64] S. Yeasmin, N. Akter, and N. Ahmed, "A novel optimization method for preparing carboxymethyl cellulose with higher yield from wheat straw .," J. Chem. , Biol. Phys. Sci., vol. 8, no. April, pp. 444-460, 2018.

[65] Sunardi, N. M. Febriani, and A. B. Junaidi, "Preparation of carboxymethyl cellulose produced from purun tikus (Eleocharis dulcis)," AIP Conf. Proc., vol. 1868, 2017.

[66] M. El-sakhawy, S. Kamel, A. Salama, and H. S. Tohamy, "PREPARATION AND INFRARED STUDY OF CELLULOSE BASED AMPHIPHILIC MATERIALS,” Cellul. Pap. Dep. Natl. Res. Cent., 2017.

[67] A. M. Bochek et al., "DISSOLUTION OF CELLULOSE IN AQUEOUS ALKALINE SOLUTIONS WITH ADDED UREA AND THIOUREA," Fibre Chem., vol. 47, no. 3, pp. 166-170, 2015.

[68] K. W. Baharin et al., "Factors Affecting Cellulose Dissolution of Oil Palm Empty Fruit Bunch and Kenaf Pulp in $\mathrm{NaOH} /$ Urea Solvent," Sains Malaysiana, vol. 47, no. 2, pp. 377-386, 2018.
[69] Runying Chen, "A STUDY OF COTTON FIBERS RECOVERED FROM A MARINE ENVIRONMEMNT," The Ohio State University, 1998.

[70] M. MdIH, A. F, and F. A. A. Polymer, "Research \& Reviews in Polymer Synthesis and Grafting of Carboxymethyl Cellulose from Environmental Pollutant Cellulosic Wastes of Textile Industry," Cellul. Chem. Technol, vol. 7, no. 2, pp. 1-10, 2016.

[71] P. Tasaso, "optimiztion of Reactiom conditions for Sythesis of carboxymethyl cellulose from Palm oil Fronds," Int. J. ofChemical Eng. Appl., vol. 6, no. 2, pp. 3-6, 2015.

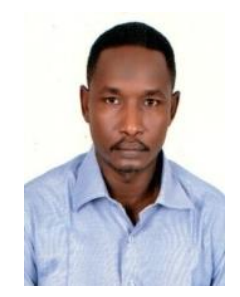

Ahmed Abdalleh Ahmed Youssif, Master of degree student, Faculty of Applied Science, Red Sea University. Work at Customs laboratory - Organic Section. His research interest is application of Lignocellulosic biomass

Taiseer Hassan Mohammed, presently working as Assistant professor in Applied Chemistry Department, Red Sea University (RSU). She did her B.E (Chemical Engineering) from RSU and MSc. degree of Engineering from Gadjah Mada University, Indonesia. PhD in Chemical Engineering from University of Abdelmalek Essaadi, Morocco. Her research interests are Valorization of Resources, renewable Energy and Environment Protection Technologies. 